\title{
The Refugee Claims System
}

by Raphael Girard

The determination of claims to refugee status did not become a public issue in Canada until well after the revocation of universal appeal rights against deportation in 1973. In the period between the enactment of the $1967 \mathrm{New}$ York protocol - which gave global expression to the 1951 refugee definition and the revocation of Section 34 of the immigration regulation in 1972 , it had been possible to apply for immigration to Canada from within the country. This possibility, coupled with universal access to appeal from deportation orders and the practice of non-deportation to countries in turmoil (particularly those in Eastern Europe), subsumed within larger flows the small numbers of asylum seekers who were beginning to come to Canada without having first been selected through immigration offices overseas.

Amendment to the Immigration Appeal Board Act in 1973 led to the first mention of refugees in an immigration statute. Refugees, along with sponsored dependents and a few other classes of visitors, were singled out to retain appeal rights when general eligibility was restricted. This in turn gave rise to the Interdepartmental Committee on Refugee Status, initially an ad hoc group of officials from the Immigration Division and the Department of External Affairs, which was charged with predetermining meritorious cases that would otherwise go to appeal.

By the mid 1970s, a number of individual case decisions had aroused such controversy that the concept of special review on humanitarian grounds was extended to cover all cases which had been rejected by the Interdepartmental Committee on the grounds that the applicant did not meet the Convention definition of a refugee. This special review was intended to ensure that de- serving cases which did not meet the full rigour of the Convention would be identified and acted upon under the special relief provisions of immigration law. This was a discretionary mechanism grounded neither in law nor regulation in the specific sense of refugee processes.

Concurrently, more and more requests were being made under Section 28 of the Federal Court Act for judicial review of deportation cases. Between 1973 and 1978, therefore, an ad hoc system of refugee protection had emerged which comprised two levels of review for refugee claims, a further review of refused claims to determine humanitarian merit, and, finally, a provision - of which claimants were increasingly availing themselves - for seeking judicial review under Section 28 of the Federal Court Act. The volume of claims, however, remained small. As late as 1977 , the annual intake was only a few hundred cases.

In the policy discussions on the refugee question during the Green Paper review and subsequent parliamentary debate (culminating in the Immigration Act of 1976), the focus was very clearly on the resettlement of refugees selected abroad, along with measures facilitating voluntary repatriation or local integration. Although the question of first asylum in Canada was fully considered at every stage of policy and legislative development, it was not debated at great length. In an address to the Commons, the Opposition immigration critic noted that some voluntary groups were urging greater access to Canada for people who intended to seek refugee status in this country. He rejected this concept as one not relevant to the Canadian situation. In addition, the United Nations had given notice of the need to negotiate a new convention on territorial asylum, a development which accounted to some extent for the brevity of the debate. It was felt, in some quarters, that the territorial-asylum discussions would cause Canada to take another look at the problem in the period following the enactment of the new law. The conference on territorial asylum, however, adjourned without conclusive results.

Several aspects of the legislation that was enacted in 1976 signalled a minimum response from Canada to its obligations under the 1951 Convention and 1967 Protocol on Refugee Status. First, all persons other than certain visitors were required to obtain visas before coming forward - a clear indication that Canada was not to be made accessible to asylum seekers. Secondly, the recognition of refugee claims by the Minister did not automatically lead to any form of immigration status. Thirdly, durable refugee status as such was not created in immigration law.

Nevertheless, the protections afforded refugees against refoulement were comprehensive. Although the provisions of the Immigration Act of 1976, which established the current claims system, did not break any new ground, the Act formalized the function of the Refugee Status Advisory Committee as an advisory body and retained provision for a second review of claims by the Immigration Appeal Board. The Immigration Act also continued to provide for special relief to be granted on humanitarian grounds. At the same time, the practice by claimants of seeking legal review of refusals from the Federal Court became even more widespread. As a result, this combination of law and practice created a refugee-determination system which afforded the claimant four distinct levels of review on request - regardless of the strength or weakness of the claim. 


\section{INQUIRY ADJOURNMENTS FOR REFUGEE CLAIMS NATIONAL}

\section{- CASES IN PROCESS -}

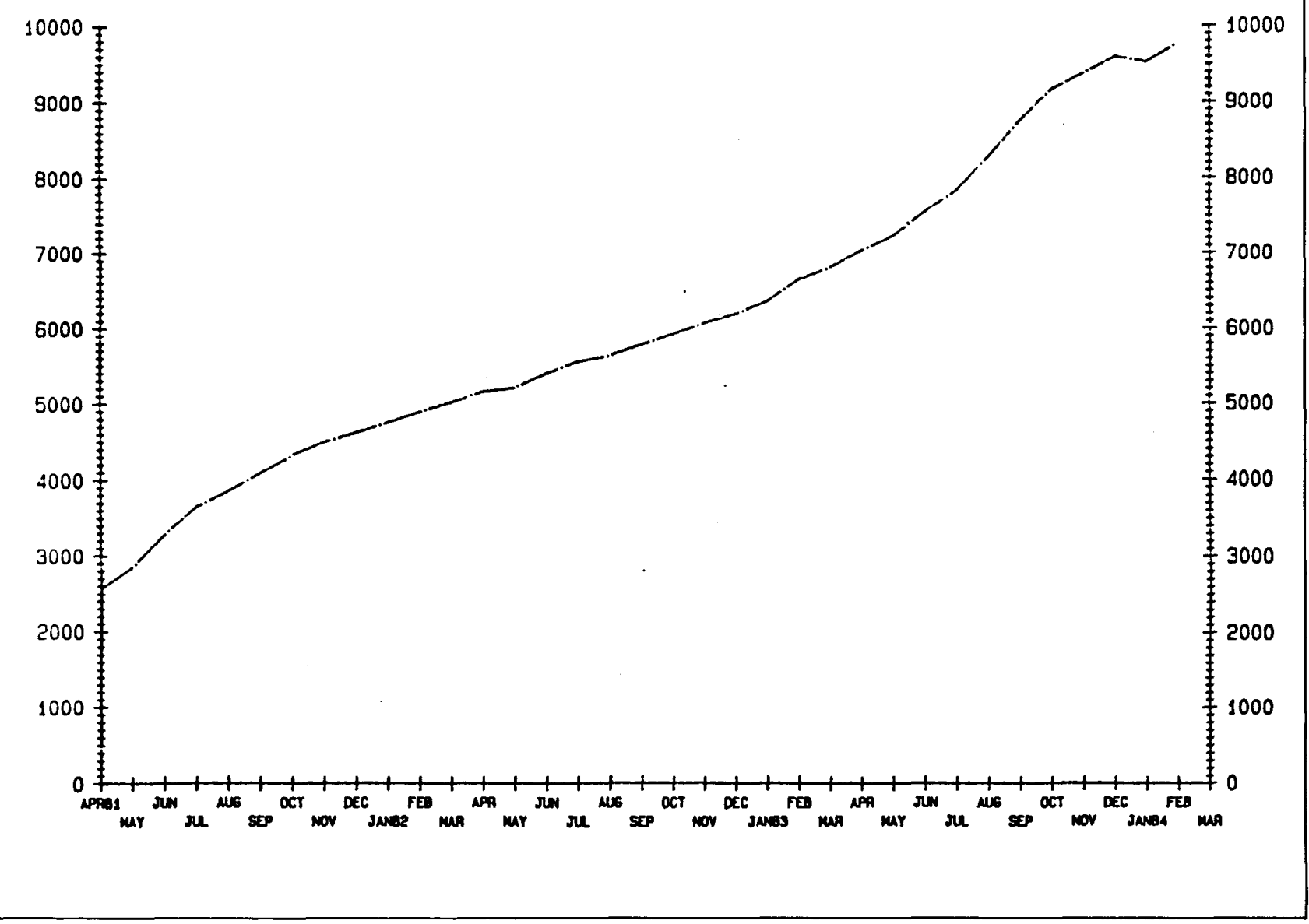

It is clear that this system does not and cannot work in the face of even a modest volume of claims. At the onset, claims were able to pass the first level of review in a reasonably short period, but it was quite another matter to move cases through all levels speedily, particularly when some marginal claimants stood to gain by such delays.

In the face of a large volume of claims, however, even the capacity for expeditiously determining claims at the first level was lost. By late 1980, an influx of claimants from India began in earn- est, clogging the system at the immigration-inquiry state and later, at the transcription of the claimant's statement under oath. By June, 1981, after three years of a relatively low-volume intake, there were 3,400 claims in the system, and this accumulation of claims was gathering speed. The average time for taking a claim to the first level was lengthening from only a few months to at least a year, owing to the growing volume and the fact that the claims were concentrated in Montreal and Toronto.
The growth in claims between 1981 and 1983 is vividly illustrated in Tables A and B. During 1983 alone, some 6,300 inquiries were adjourned for the purpose of allowing the person concerned to make a refugee claim. In 1983 , as well, only 3,300 transcripts were completed and forwarded to the RSAC. Less than 2,500 cases were finally determined.

The decision-making process was improved by experiments with oral hear-

(Continued on p. 10) 


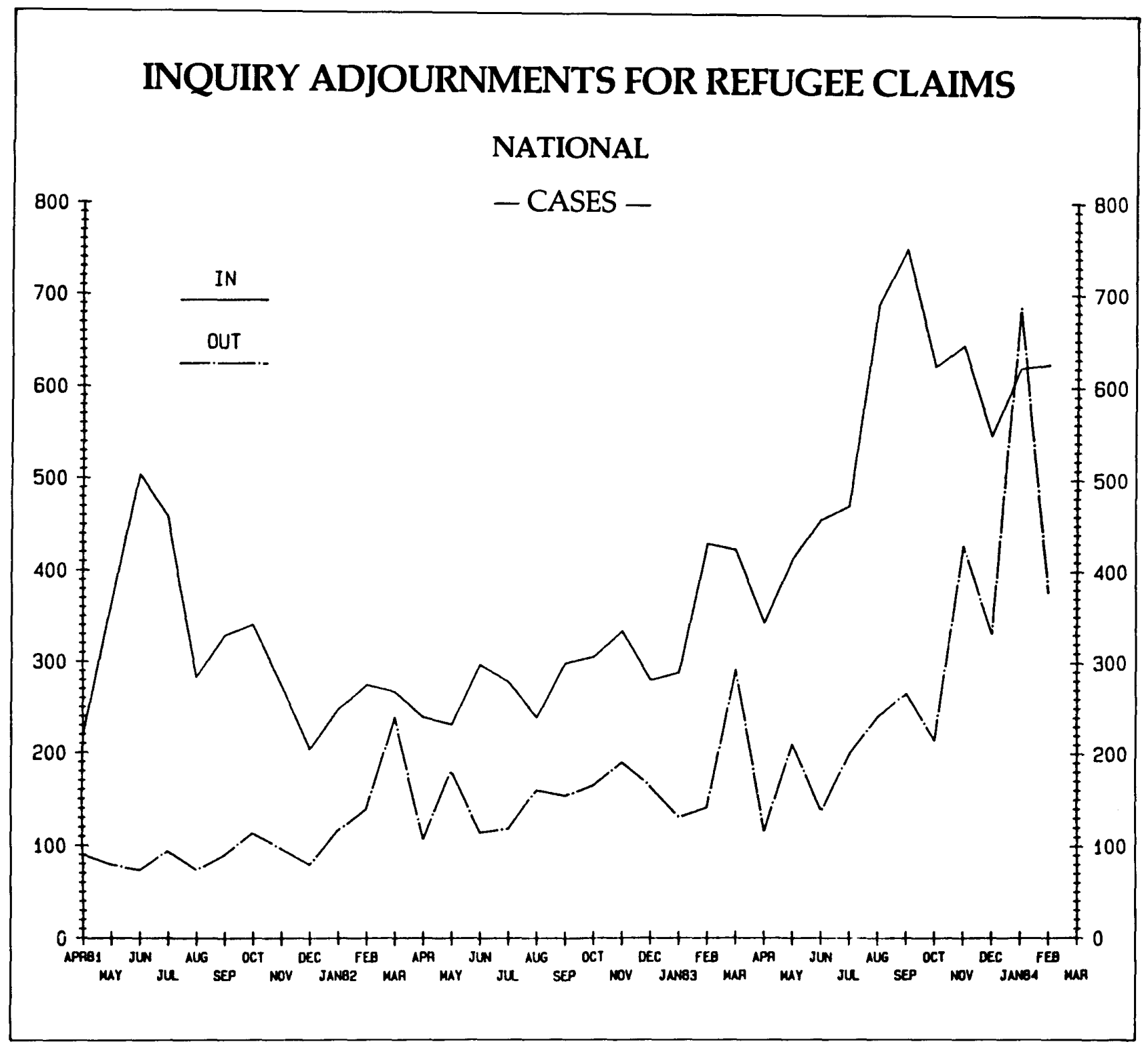

ings of claims and by the implementation of new guidelines at the RSAC, but productivity still declined - largely because fewer claims were rejected as manifestly unfounded under guidelines approved by the former Minister, the Honourable Lloyd Axworthy.

At the Immigration Appeal Board, the wait for a full hearing now averages one year, despite the fact that $95 \%$ of claims are rejected in chambers.

Beyond this stage, there are an esti- mated 2,000 cases in the judicial system.

As a result, Canada has an extremely elaborate system for the review of refugee claims - one which is too slow in identifying genuine refugees and consumes an inordinate share of administrative and judicial resources in dealing with issues which are not essentially of a judicial nature.

It is important not to lose sight of the fact that the determination of refugee status is a serious matter, and that the consequences of error can be drastic. Nevertheless, it is patently obvious that the current Canadian system needs to be amended, both in order to protect the interests of the bona fide refugee and to maintain Canada's control over the entry of those migrants who would seek to remain by any means.

$M r$. Girard is director of Refugee Affairs for Employment and Immigration Canuda. 